\title{
Diversity and Geographic Distribution of Dog Tick Species In Sri Lanka and The Life Cycle of Brown Dog Tick, Rhipicephalus Sanguineus Under Laboratory Conditions
}

\author{
Rupika Subashini Rajakaruna ( rupikar@pdn.ac.lk) \\ University of Peradeniya https://orcid.org/0000-0001-7939-947X
}

\section{Research Article}

Keywords: Diversity, Geographic Distribution, Life Cycle, Dog Ticks, Sri Lanka

Posted Date: July 19th, 2021

DOI: https://doi.org/10.21203/rs.3.rs-721544/v1

License: @ (i) This work is licensed under a Creative Commons Attribution 4.0 International License. Read Full License 


\section{Abstract \\ Background}

Tick infestations and canine tick-borne diseases have become a major emerging health concern of dogs in Sri Lanka. Information about tick species infesting dogs and their geographic distribution in Sri Lanka is largely unknown.

\section{Methods}

An island-wide, cross-sectional survey of tick species infesting the domestic dog was carried out, and the life cycle of the major dog tick, Rhipicephalus sanguineus was studied under laboratory conditions.

\section{Results}

A total of 3,026 ticks were collected from 1,219 dogs of different breeds in all 25 districts in the three climatic zones: Wet, Dry, and Intermediate zones. Eight species in five genera were identified: $R$. sanguineus (63.4\%), Rhipicephalus haemaphysaloides (22.0\%), Haemaphysalis bispinosa (12.5\%), Haemaphysalis intermedia (0.9\%), Haemaphysalis turturis (0.6\%), Amblyoma integrum (0.4\%), Dermacentor auratus (0.2\%) and Hyalomma sp (0.06\%). The brown dog tick, $R$. sanguineus was the dominant species in the Dry and Wet zones, while $R$. haemaphysaloides was the dominant species in the Intermediate zone. Species diversity (presented as Shannon diversity index H) in the three was 1.135, 1.021and 0.849 in Intermediate, Dry and Wet zones, respectively. Adults formed $94.7 \%$ with a significantly higher number of females, and the rest were nymphs. Rhipicephalus sanguineus preferred the anterior side of the host body, specifically the inner and outer side of the ear. In contrast, $R$. haemaphysaloides preferred the posterior side, mainly the fore and hind limbs. The three-host life cycle of $R$. sanguineus was completed within 70-126 days, all three stages successfully fed on the New Zealand white rabbits under laboratory conditions. The mean REI and RFI were $50.8 \pm 9.69$ and $9.1 \pm 5.01$, respectively. Larger females had higher reproductive success.

\section{Conclusion}

The dominant dog tick species and the species diversity varied in different climatic regions of Sri Lanka. Information on diversity, distribution and life cycle parameters is fundamental for studies of canine tick-borne infections, zoonoses, and their epidemiology.

\section{Background}

Dog ticks are particularly important because dogs are companion animals with worldwide distribution, and their unrestricted movement may carry ticks and tick-borne pathogens to new habitats. Ticks transmit a wide variety of infectious agents to dogs. These diseases are of great concern because of costs for owners, suffering in dogs, and the risk of transmission of pathological agents from dogs to humans. Information on tick species infesting dogs is vital for the studies on tick-borne diseases and their control and prevention. Tick-borne diseases of dogs have recently become a significant focus of interest globally, especially in areas of the world in which they have traditionally been considered non-endemic. The concern that these diseases might become established in new geographical locations arose from the increased international mobility of dogs and increased contact of these animals with non-urban environments and wildlife disease reservoirs (Shaw et al., 2001). Ticks, especially the larval stage, can travel globally undetected with pets and other animal trade. Therefore, the potential impacts of increased movement between countries of people and global pet trade on the distribution of ticks is currently an area of increasing public health concern. Historical records and recent studies in the British Isles show that the distribution of Ixodes ricinus in Great Britain has expanded by $17 \%$, and abundances of ticks have increased in most of the locations surveyed (Kirby et al., 2004; Pietzsch et al., 2005; Scharlemann et al., 2008). Moreover, in Central Europe, I. ricinus has expanded its geographic range northwards and upwards to altitudes of up to $1100 \mathrm{~m}$ (Daniel et al., 2009) wherein a study carried out in 1965, I. ricinus was not recorded above $700 \mathrm{~m}$ (Cerny et al., 1965). Together with the ticks, the distribution of tick-borne infections has also been expended. For example, tick-borne encephalitis in mountainous regions of the Czech Republic (Daniel et al., 2009) and the increase in human cases of Lyme disease by 30fold between 1999 and 2008 in Scotland (Health Protection Scotland, 2009). The expansion of the tick-borne infections among animals vector of canine babesiosis in Europe by the European meadow tick, Dermacentor reticulatus is extended northwards into Poland, Belgium, Germany, the Netherlands, and southern England (Matjila et al., 2005; Dautel et al., 2006; Jameson and Medlock, 2009; Zygner et al., 2009).

Among the tick species that infest dogs, Rhipicephalus sanguineus, the brown dog tick is the most commonly known species with a three-host life cycle. It feeds primarily on dogs and occasionally on other hosts, including humans. It has a wide distribution worldwide and is a known vector of pathogens such as Babesia canis, Ehrlichia canis, Rickettsia conorii, and Leishmania spp (Dantas-Torres, 2011; Dantas-Torres et al., 2012). Other tick species of dogs recorded include: Ixodus ricinus, I. hexagonus, I. canisuga from Great Britain (Smith et al., 2011), Haemaphysalis longiconis, H. falva, I avatus, H. hystricis, I. persulcatus, I. nipponensis, A. testudinarium from Japan (Shimada et al., 2003), I. dammini and Dermacentor variabilis from the USA (Anderson and Magnarelli, 1980). All three stages in the life cycle, the larva, nymph and adults, feed primarily on dogs and each stage drops off after feeding and moulting occur off-host. This tick occasionally infests other hosts, including humans. The life cycle takes up to two years to complete in nature (Sonenshine, 1991). However, under laboratory conditions, $R$. sangenius completes its entire life cycle within 17 weeks (Troughton and Levin, 2007).

Few studies have reported the tick species of wild and domesticated animals in Sri Lanka (Seneviratne, 1965; Liyanaarachchi et al., 2013; 2015a; Diyes and Rajakaruna 2015). Liyanaarachchi et al., (2015b) surveyed the ticks infesting dogs together with other wild and domesticated animals and reported eight tick species: D. auratus, Ha. turturis, Ha. cuspidata, A. testudinarium, A. clypeolatum, Ha. spinigera, Hy. isaaci, and Ha. aculeata on dogs. Later, a study detected spotted fever group rickettsia in $R$. sanguineus collected from a dog (Liyanaarachchi et al., 2015b). However, all the above studies are restricted to one or a few 
locations in the country. Surveillance data on tick species' diversity and geographic distribution is important because it will provide valuable baseline information to detect future changes in tick prevalence and distribution patterns.

\section{Materials And Methods Objectives}

The present study was carried out to determine the tick species infesting the dogs, their distribution in different climatic zones in Sri Lanka, and to describe the life cycle parameters of the dominant dog tick species under laboratory conditions.

\section{Study design}

First, a descriptive, island-wide survey was conducted to assess the diversity and distribution of dog ticks. Then, the life cycle of the major tick species encountered during the survey was was carried out using New Zealand white rabbits (Oryctolagus cuniculus) under controlled laboratory conditions.

\section{Geographic distribution and diversity of ticks infesting domestic dogs}

Tick infesting the domestic dog (Canis lupus familiaris) of different breeds, sex and age were collected from all of the districts covering the Dry, Wet, and Intermediate zones of Sri Lanka using a non-probability convenient sampling technique. At least five towns/ villages were selected from each district, and each site was visited and sampled only once. However, in certain districts where the dogs were fewer in number, less than ten dogs were sampled, where there were more dogs, more than ten were sampled. All the ticks in one-half of the host were added to the collection.

Only the ticks that were attached on to the host and feeding were collected. Ticks were located by visual appraisal and by running the hand over the dog's body. Ticks were removed using a pair of tweezers or/and fingers to grasp the tick as close to the skin surface as possible. Specimens were preserved in absolute alcohol. The preferred attachment site was determined by dividing the host body into ten different regions, ear (dorsal, inner sides), eyelids, neck, body, face, tail region, snout, forelimb pads, and hind limb pads. Information about the breed, age, sex of the dogs and the site of attachment of the tick, the intensity of infection were noted. Ticks were brought to the laboratory, observed under dissecting microscope, and identified using available standard keys and literature. The number/percentage of different life cycle stages, species diversity according to the district, climatic zone, and diversity index (Shannon diversity index) was calculated. Descriptive statistics like percentages and ratios were calculated and bivariate analysis chi-squared test was utilized to see the independence of categories among gender etc.

Life cycle of Rhipicephalus sanguineus under laboratory conditions

Rhipicephalus sanguineus was the most abundant and widely distributed dog tick species; thus, its life cycle parameters were studied in a colony established by collecting engorged females in the Kandy district from four localities. They were kept under laboratory conditions (Temperature $27 \pm 1^{\circ} \mathrm{C}$; Relative humidity $70 \%-80 \%$ ) and were allowed to lay eggs. Life stages were fed on the New Zealand white rabbits (Oryctolagus cuniculus). After hatching, 100 larvae were added into a plastic feeding vial glued onto the rabbit's clean-shaved skin. Then, the larvae were allowed to feed, and once they dropped off, they were transferred to sampling vials and allowed to moult. When larvae moulted, the nymphs (20) were introduced to the feeding chamber and allowed to feed on the rabbit. Once the engorged nymphs dropped off, they were also kept to moult under laboratory conditions. Adults $(n=15)$ were also introduced to the feeding chamber and allowed to feed. Fully engorged females and males also were kept in laboratory conditions to determine the survival. Biological parameters such as the weight of the wild-caught females, pre-oviposition period, oviposition period, incubation period of eggs, the parasitic period of larva, nymph, and adult were recorded. Then the Reproductive Efficiency Index (REl; the weight of eggs laid/weight of the engorged females*100), percentage of eclosion (percentage of hatched eggs with respect to the total number of eggs laid by each female) and Reproductive Fitness Index (RFl; number of eggs that hatched into larvae/weight of the engorged females in $\mathrm{mg}$ ) were calculated. Pearson correlation of weight of the female and the reproductive parameters were computed using Minitab 17 version. All the study protocols were read and approved by the Ethical Review Committee at the Postgraduate Institute of Science, University of Peradeniya, Sri Lanka.

\section{Results}

\section{Geographic distribution and diversity of ticks infesting domestic dogs}

A total of 3,026 ticks were collected from 1,219 dogs of different breeds in the 25 districts in Sri Lanka. The collection consisted of five genera of hard ticks belonging to eight species: Rhipicephalus sanguineus, Rhipicephalus haemaphysaloides, Haemaphysalis intermedia, Haemaphysalis bispinosa, Haemaphysalis turturis, Amblyomma integrum, Hyalomma sp. and Dermacentor auratus (Family Ixodidae; Fig. 1). Adults and nymphs of four species were recorded; $R$. sanguineus, $R$. haemaphysaloides, Haemaphysalis intermedia and $H$. bispinosa while only the nymphs of $D$. auratus and $A$. integrum and only the adults of Hyalomma sp. and $H$. tuturis were recorded (Table 1). Adults formed $94.7 \%$ of the collection with a significantly higher number of females (54.8\%) was in the collection than males $\left(40.0 \% ; \chi^{2}=40.3787, p<0.0001\right)$. 
Table 1

Species and the life stage of ticks infesting dogs in Sri Lanka $(n=3,026)$

\begin{tabular}{|c|c|c|c|c|}
\hline \multirow[t]{2}{*}{ Tick species } & \multicolumn{3}{|l|}{ Adults (\%) } & \multirow{2}{*}{$\begin{array}{l}\text { Nymphs } \\
\text { (\%) }\end{array}$} \\
\hline & Females & Males & Total & \\
\hline Rhipicephalus sanguineus & $1040(54.2)$ & $774(40.4)$ & $1,817(94.6)$ & $104(5.4)$ \\
\hline Rhipicephalus haemaphysaloides & $299(44.8)$ & $343(51.4)$ & $642(96.3)$ & $25(3.7)$ \\
\hline Haemaphysalis intermedia & $288(76.2)$ & $80(21.2)$ & $368(97.4)$ & $10(2.6)$ \\
\hline Haemaphysalis bispinosa & $10(58.8)$ & $5(29.4)$ & 15 (88.2) & $2(11.8)$ \\
\hline Haemaphysalis turturis & $19(73.1)$ & $7(26.9)$ & $26(100.0)$ & - \\
\hline Amblyomma integrum & - & - & - & $13(100.0)$ \\
\hline Hyalomma sp. & $1(50.0)$ & $1(50.0)$ & $2(100.0)$ & - \\
\hline Dermacentor auratus & - & - & - & $5(100.0)$ \\
\hline
\end{tabular}

In Sri Lanka, Rhipicephalus sanguineus was the dominant dog tick species ( $n=1,918,63.4 \%$; Table 2$)$. It was the most common dog tick in all the districts except in Polonnaruwa, Nuwara-Eliya, Monaragala, Badulla and Mannar. In these exceptions, $R$. haemaphysaloides was the dominant species, which was the second most common tick $(n=667,22.0 \%)$ infesting dogs in Sri Lanka. The least common species was Hyalomma spp. (0.06\%) found only in the Vavuniya district (Table 3; Fig. 2). In the three climatic zones, $R$. sanguineus was the dominant species encompassing $73.8 \%$ in the Wet zone and $58.6 \%$ in the Dry zone, whereas Rhipicephalus haemaphysaloides was the dominant species (42.0\%) and R. sanguineus (34.3\%) was the second most dominant species in the Intermediate zone. Haemaphysalis bispinosa was recorded from all three zones, but the distribution was limited to some districts such as Anuradhapura, Polonnaruwa, Matale, Ampara, and Matara. Haemaphysalis turturis were only found from Daraniyagala, Trincomalee, and Kilinochchi, while Hyalomma sp. was found only from the Vavuniya district (Fig. 2). Amblyomma integrum was restricted to the Wet and Intermediate zones.

Table 2

Distribution of tick species in the Wet, Dry and Intermediate zones $(n=3,026)$

\begin{tabular}{|c|c|c|c|c|c|}
\hline \multirow[t]{3}{*}{ Tick species } & \multicolumn{4}{|c|}{ No. of Ticks (Percentage of species in a zone) } & \multirow{3}{*}{$\begin{array}{l}\text { Total No. } \\
\text { (Overall \%) }\end{array}$} \\
\hline & \multirow{2}{*}{$\begin{array}{l}\text { Wet } \\
\text { zone }\end{array}$} & \multirow{2}{*}{\multicolumn{2}{|c|}{$\begin{array}{l}\text { Dry } \\
\text { zone }\end{array}$}} & \multirow{2}{*}{$\begin{array}{l}\text { Intermediate } \\
\text { zone }\end{array}$} & \\
\hline & & & & & \\
\hline Rhipicephalus sanguineus & $1,036(73.8)$ & $785(58.6)$ & $97(34.3)$ & & $1,918(63.4)$ \\
\hline Rhipicephalus haemaphysaloides & $192(13.7)$ & $356(26.6)$ & $119(42.0)$ & & $667(22.0)$ \\
\hline Haemaphysalis intermedia & $12(0.9)$ & $14(1.0)$ & $0(0.0)$ & & $26(0.9)$ \\
\hline Haemaphysalis bispinosa & $143(10.2)$ & $173(12.9)$ & $62(21.9)$ & & $378(12.5)$ \\
\hline Haemaphysalis turturis & $8(0.6)$ & $9(0.7)$ & $0(0.0)$ & & $17(0.6)$ \\
\hline Amblyomma integrum & $8(0.6)$ & $0(0.0)$ & $5(38.5)$ & & $13(0.4)$ \\
\hline Hyalomma sp. & $0(0.0)$ & $2(0.1)$ & $0(0.0)$ & & $2(0.1)$ \\
\hline Dermacentor auratus & $5(0.4)$ & $0(0.0)$ & $0(0.0)$ & & $5(0.2)$ \\
\hline Total & $1,404(46.4)$ & \multicolumn{2}{|c|}{$1,339(44.2)$} & $283(9.4)$ & 3,026 \\
\hline Shannon Diversity Index $(H)$ & 0.849 & \multicolumn{2}{|c|}{1.021} & 1.135 & 0.991 \\
\hline
\end{tabular}


Distribution of tick sp€

\begin{tabular}{|c|c|c|c|c|c|c|c|c|c|c|}
\hline \multirow[t]{2}{*}{ Tick Species } & \multicolumn{10}{|c|}{ Number of ticks recorded in each district } \\
\hline & Hambantota & Ampara & Trincomalee & Kilinochchi & Anuradhapura & Vavuniya & Puttlam & Batticaloa & Jaffna & Monargala \\
\hline R. sanguineus & 92 & 5 & 143 & 31 & 52 & 35 & 20 & 62 & 305 & 25 \\
\hline $\begin{array}{l}R . \\
\text { haemaphysaloides }\end{array}$ & 40 & 32 & 12 & 7 & 37 & 20 & 32 & 25 & 25 & 55 \\
\hline H. turturis & - & - & 6 & 8 & - & - & - & - & - & - \\
\hline H. intermedia & 25 & 10 & 16 & 1 & 51 & - & 6 & 12 & 2 & 5 \\
\hline H. bispinosa & 1 & 2 & - & - & 4 & - & - & - & - & - \\
\hline A. integrum & - & - & - & - & - & - & - & - & - & - \\
\hline Hyalomma sp & - & - & - & - & - & 2 & - & - & - & - \\
\hline D. auratus & - & - & - & - & - & - & - & - & - & - \\
\hline
\end{tabular}

\section{Site of attachment}

Most ticks were attached to the anterior part of the body, especially the head region, than the posterior side with one exception, Rh. haemophysaloides which preferred the rear side of the host (Table 4). The most common species $R h$. sanguineus preferred head region, specifically inner and outer ear, whereas $R h$. haemaphysaloides were found attached to limbs, mostly the hind limbs (Table 4).

Table 4

Attachment site of the tick species on the host body

\begin{tabular}{|c|c|c|c|c|c|c|c|c|c|c|c|c|c|}
\hline \multirow[t]{2}{*}{ Stage } & \multirow[t]{2}{*}{ Tick species } & \multicolumn{10}{|c|}{ Percentage of ticks } & \multirow{2}{*}{$\begin{array}{l}\text { Total anterior } \\
(\%)\end{array}$} & \multirow{2}{*}{$\begin{array}{l}\text { Total } \\
\text { posterior } \\
(\%)\end{array}$} \\
\hline & & $\begin{array}{l}\text { Eye } \\
\text { lids }\end{array}$ & $\begin{array}{l}\text { Inner } \\
\text { ear }\end{array}$ & $\begin{array}{l}\text { Outer } \\
\text { ear }\end{array}$ & Snout & Face & Body & Neck & Tail & $\begin{array}{l}\text { Fore } \\
\text { Limb }\end{array}$ & $\begin{array}{l}\text { Hind } \\
\operatorname{limb}\end{array}$ & & \\
\hline \multirow[t]{6}{*}{ Adult } & R. sanguineus & 7.2 & 25.5 & 21.4 & 0.8 & 1.5 & 4.1 & 5.5 & 0.4 & 21.1 & 12.3 & 54.9 & 44.9 \\
\hline & $\begin{array}{l}\text { R. } \\
\text { haemaphysaloides }\end{array}$ & 10.5 & 14.8 & 20.9 & 1.2 & 2.1 & 5.9 & 8.7 & 0.0 & 28.1 & 15.1 & 47.4 & 59.9 \\
\hline & H. intermedia & 35.5 & 12.1 & 10.2 & 0 & 1.2 & 0 & 0.2 & 0 & 28.1 & 13.9 & 57.8 & 42.2 \\
\hline & H. bispinosa & 0 & 85.7 & 4.3 & 0 & 0 & 0 & 0 & 0 & 0 & 0 & 100 & 0 \\
\hline & H. turturis & 0 & 100 & 0 & 0 & 0 & 0 & 0 & 0 & 0 & 0 & 100 & 0 \\
\hline & Hyalomma sp. & 0 & 100 & 0 & 0 & 0 & 0 & 0 & 0 & 0 & 0 & 100 & 0 \\
\hline \multirow[t]{4}{*}{ Nymphs } & R. sanguineus & 0 & 88.0 & 0 & 0 & 0 & 0 & 0 & 0 & 8 & 4 & 88.0 & 12.0 \\
\hline & $\begin{array}{l}\text { R. } \\
\text { haemaphysaloides }\end{array}$ & 0 & 0 & 0 & 0 & 0 & 0 & 0 & 0 & 61.0 & 39.1 & 0 & 100 \\
\hline & A. integrum & 92.1 & 8.0 & 0 & 0 & 0 & 0 & 0 & 0 & 0 & 0 & 100 & 0 \\
\hline & D. auretus & 0 & 100 & 0 & 0 & 0 & 0 & 0 & 0 & 0 & 0 & 100 & 0 \\
\hline
\end{tabular}

Life cycle parameters of Rhipicephalus sanguineus

The engorged, wild-caught females had a mean weight of 133.2 (54-187) mg and completed oviposition in $14.0 \pm 3.47$ days with a pre-oviposition period of $4.9 \pm 1.02$ days (Tables 4 and 5). The mean number of eggs laid by a female was $1444.3 \pm 531.08(101-2708)$ (Table 5). The egg incubation period was 29.6 \pm 3.96 days (range 20-43 days; Table 4). Larvae had a mean parasitic period of $3.1 \pm 0.56$ days, and of the larvae introduced $62.7 \%$ successfully fed and dropped off for moulting (Tables 4 and 5). Of those engorged larvae, 31.1\% moulted into nymphs after a moulting period of $13.4 \pm 1.32$ days (Tables 4 and 5 ). The nymphs fed for $5.0 \pm 0.0$ days, dropped off and spent a moulting period of $14.3 \pm 0.48$ days. The parasitic period of adult females was $12.6 \pm 2.94$ days (Table 4). 
Table 5

Life cycle parameters of $R$. sanguineus fed on New Zealand white rabbits under laboratory conditions

\begin{tabular}{|llllll|}
\hline \multirow{2}{*}{ Life stage } & Parameter & \multicolumn{4}{c|}{ Number of days } \\
\cline { 3 - 6 } & & Mean & SD & Minimum & Maximum \\
\hline \multirow{2}{*}{ Female* } & Pre-oviposition & 4.9 & 1.02 & 4 & 7 \\
\cline { 2 - 6 } & Oviposition period & 14.0 & 3.47 & 3 & 19 \\
\cline { 2 - 6 } & Post-oviposition survival & 1.1 & 0.99 & 1 & 5 \\
\hline Eggs & Incubation period & 29.6 & 3.96 & 20 & 43 \\
\hline Larva & Parasitic period & 3.1 & 0.56 & 2 & 3 \\
\cline { 2 - 6 } & Moulting period & 13.4 & 1.32 & 13 & 14 \\
\hline Nymph & Parasitic period & 5.0 & 0.00 & 5 & 5 \\
\cline { 2 - 6 } & Moulting period & 14.3 & 0.48 & 13 & 15 \\
\hline Female & Parasitic period & 12.6 & 2.94 & 9 & 15 \\
\hline *Wild caught females SD-Standard Deviation & & & \\
\hline
\end{tabular}

The REI and RFI values were $50.8 \pm 9.69(22.0-70.0)$ and $9.1 \pm 5.01(0-22.6)$ and $8.8(1.8-20)$, respectively (Table 5). Male: female sex ratio was 5:2 in laboratory-raised adults. The number of eggs laid increased rapidly within the first three days and gradually decreased. There were positive correlations found between the female weight and three reproductive parameters tested; the total number of eggs laid, the number of eggs hatched, and the weight of the egg mass (Pearson correlation: $r=0.468,0.355,0.896$ respectively; $p<0.05$ : Table 6 , Fig. 3 ). The egg-laying potential of an engorged female is directly related to her capacity to feed; therefore, heavier females showed the highest values in the number of eggs laid as well as the weight of the egg mass, and after that, a higher hatch rate. However, no significant correlations were found between the three calculated reproductive parameters (REI, RFI and percent eclosion) with the female weight ( $p>0.05$; Table 6 and Fig. 4). Generally, higher females have shown higher REI and percent eclosion in contrast, RFI showed a negative relationship with the female weight. Nonetheless, the regression fit does not fully explain REl, $\mathrm{RFI}$ or percent eclosion since the $\mathrm{R}^{2}$ values were $<5.0 \%$ (Fig. 4 ).

Table 6

Biological parameters of $R$. sanguineus fed on New Zealand White rabbits under laboratory

\begin{tabular}{|lllll|}
\hline Parameter & Mean & SD & Minimum & Maximum \\
\hline *Engorged females weight (mg) & 109.7 & 35.09 & 25.0 & 200.0 \\
\hline *Number of eggs laid by engorged females & 1444.3 & 531.08 & 101 & 2708 \\
\hline *Reproductive Fitness Index (RFI) & 9.1 & 5.01 & 0.0 & 22.6 \\
\hline *Reproductive Efficiency Index (REI) & 50.8 & 9.69 & 22.0 & 70.0 \\
\hline *Percent eclosion & 63.0 & 22.72 & 0.0 & 95.4 \\
\hline Parameter & & Percentage & \\
\hline Feeding success of larvae & 62.7 & & & \\
\hline Moulting success of larvae to nymph & 31.7 & & & \\
\hline Feeding success of nymphs & 77.0 & & & \\
\hline Moulting success of nymph to adult & 86.9 & & & \\
\hline Feeding success of Adult & 50.0 & & & \\
\hline *Wild caught females SD-Standard Deviation & & & \\
\hline
\end{tabular}


Table 7

Correlation (Pearson Correlation) between reproductive parameters and the female weight of wild caught females of $R$. sanguineus

\begin{tabular}{|lll|}
\hline Reproductive parameter & R & p \\
\hline Total laid eggs per female & 0.468 & $0.001^{*}$ \\
\hline Total hatched eggs per female & 0.355 & $0.014^{*}$ \\
\hline Weight of egg mass per female & 0.896 & $<0.001^{*}$ \\
\hline Reproductive Fitness Index (RFI) & 0.181 & 0.224 \\
\hline Reproductive Efficiency Index (REI) & 0.162 & 0.277 \\
\hline Percent eclosion & 0.223 & 0.132 \\
\hline *indicate the significance $p<0.05$ & & \\
\hline
\end{tabular}

All the life cycle stages, including larvae, nymphs, and adults successfully fed on the New Zealand white rabbits under controlled laboratory conditions and completed their life cycle within 70-126 (mean $98 \pm 14.74$ ) days (Table 5).

\section{Discussion}

The survey results showed brown dog tick, Rh. sangenius was the major tick species that infest domestic dogs island-wide. More than fifty years ago, Seneviratne in 1965 reported Rh. sanguineus as the most frequently found tick on dogs in Ceylon (now Sri Lanka). It is also the most widespread dog tick worldwide (Dantas-Torres, 2010). This tick can be found on dogs living in both urban and rural areas, being highly adapted to live within human dwellings and being active throughout the year not only in tropical and subtropical regions, but also in some temperate areas (Dantas-Torres, 2010). Although dog is the main host, it has also been recorded on other animals like wild canids (Labruna et al., 2005) and a wide range of wild and domestic animals of Sri Lanka including ox, horse, buffalo, cat, goat, sheep, and also humans (Seneviratne 1965; Diyes and Rajakaruna, 2015; Ariyarante et al., 2016; Liyanaarachchi et al., 2015a). This indicates that free-ranging wild animals might be involved in its maintenance and dispersion through different regions. This could have implications in tick control and in the epidemiology of tick-borne diseases, particularly in areas where dogs live in close contact with wildlife (Dantas-Torres, 2010). Studies have shown that some dog breeds appear to be more resistant than others to infestations by Rh. sanguineus (Louly et al., 2009). The local mongrels crossbred with different breeds or crossbred with the local Sinhala hound or Sinhalese hound belonging to the species Sinhala sunakaya which is found in Sri Lanka and parts of India seem to be more resistant to tick bites, but further studies are needed to assess the dog breed susceptibility to ticks. This tick was attached everywhere on the dog but the preferred site was the head region, consistent with the review of Dantas-Torres, 2010 where he reported that $R h$. sanguineus ticks can attach everywhere on the dog, but the head (particularly on ears), interdigital spaces, back, inguinal region, and axilla are among their preferred attachment sites. Dantas-Torres, 2011 showed that adult $R h$. sanguineus generally feed on sites (e.g., ears) that make it difficult for dogs to remove them, whereas immatures feed on lower areas of the dog's body (e.g., belly, rump, and hind legs), probably because of their more limited mobility. Rhipicephalus sanguineus is the most important species from the veterinary standpoint as it a vector of many pathogens affecting dogs and occasionally humans (Regendanz and Muniz 1936; Ewing et al., 2002; Forlano et al., 2005; Dantas-Torres, 2010). It is known to carry many pathogens, including Babesia vogeli, Ehrlichia canis, Hepatozoon canis, Rickettsia conorii and Rickettsia rickettsii, the last two also been responsible for disease in humans (Dantas-Torres et al., 2012). Liyanaarachchi et al. (2015b) detected DNA of spotted fever group rickettsiae in Rh. sangenius collected from a domestic dog in Sri Lanka.

In addition to Rh. sanguineus, seven other species were recorded in dogs: Rhipicephalus haemaphysaloides, Haemaphysalis bispinosa, Haemaphysalis intermedia, Haemaphysalis turturis, Amblyoma integrum, Dermacentor auratus and Hyalomma sp. Previously, Seneviratne (1965) reported six species of ticks, Rh. sanguineus, Rh. haemaphysaloides, H. intermedia, H. bispinosa, Boophilus sp, A. integrum (immature stages) collected from dogs in Sri Lanka. Later, Liyanaarachchi et al. (2015a) recorded 14 species of ticks including, $R$ h. sanguineus, Rh. haemaphysaloides, H. intermedia, H. bispinosa, $R$. microplus, $A$. integrum, H. cuspidata, H. spinigera, H. aculeata, A. testudinarium, A. clypeolatum, Hy. isaaciand D. auratus from dogs. Compared to these previous studies, previously recorded six species, Rh. microplus, H. cuspidata, H. spinigera, H. aculeata, A. testudinarium and A. clypeolatum were not reported in the present study. Some of these rare species could be accidental occurrences due to close contact of dogs with livestock and wildlife.

Rhipicephalus haemaphysaloides was the second most common tick on dogs recorded from all over the island with a wide geographical distribution but is less common at elevations above $3000 \mathrm{ft}$. It was the dominant dog tick species in the Intermediate zone specially in Polonnaruwa, Nuwara-Eliya, Monaragala, Badulla and Mannar districts. Although rare in urban areas, it was common in rural areas and areas closer to the forests. It has a limited distribution in the world occurring over the Oriental and parts of the Palaearctic and Australasian zoogeographic regions from Afghanistan in the west to the Philippines and Indonesia in the east and in the Indian subcontinent (Seneviratne, 1965; Walker, 2000; Guglielmone et al., 2010). It is known to infest all domestic animals, including ox, water buffalo, and horse but more commonly seen on sheep and goats (Seneviratne 1965; Diyes and Rajakaruna 2015). This tick species has a great potential for the transmission of Kaysanur forest disease virus in India (Bhat et al., 1978) and Rickettsia rhipicephali inTaiwan (Hsu et al., 2011), and as the principal vector of bovine babesiosis (e.g. Babesia orientalis) in China (Liu et al., 2007).

Three species of Haemaphysalis were recorded in the present study: $H$. intermedia, H. bispinosa and $H$. turturis, among which $H$. intermedia was widely distributed in all the districts in all three agro-climatic zones but the abundance was low. In 1965 , Seneviratne also reported that $H$. intermedia was a widespread tick species in Sri Lanka and collected from all domestic animals throughout the island. These two species, $H$. bispinosa, and $H$. intermedia are the major goat tick in Sri Lanka (Diyes and Rajakaruna 2015) and it also infests cattle (unpublished observations). Globally, H. bispinosa has a limited 
geographical distribution, being restricted to certain parts of Southern India and Sri Lanka. Haemaphysalis turturis was a rare species found only from Kagalle, Kilinochchi and Trincomalee Districts.

Dermacentor auratus and Hyalomma sp. were recorded from only one location in the Kandy and Vavuniya Districts, respectively. The primary host of $D$. auratus in wild boar and the tick has an island-wide distribution and a rapid increase in the population has been observed due to restricting the killing of wild boars. Nymphs of $D$. auratus have been identified as the major tick species responsible for human otoacariasis in Sri Lanka (Edussuriya and Weilgama 2003; Ariyarathne et al. 2016; Bandaranayke et al., 2021). Dogs also carry this tick species, and it is possible when the wild boars visit the human habitats, the engorged females, drop-off and lay eggs and larvae can be easily picked by dogs as well as humans. Hyalomma sp was only found from one location in dry zone. According to the Seneviratne in 1965, they collected ticks from buffalo, neat cattle and goats but not from the dogs. This result of the present study may be an accidental occurrence and may be due to their contact with cattle.

Immature stages of Amblyomma integrum were recorded from several locations in Rathnapura, Matara, Monaragala and Badulla districts. This species is very widespread in Sri Lanka and is more common in the jungle areas (Liyanaarachchi et al, 2015a). According to Senevirathne 1965 the incidence of $A$. integrum was lower in the higher elevations around Nuwara-Eliya which is similar with the present study and the more thickly populated parts of the Western Province which is not similar with the present study.

All the life stages except larvae of $R$. sangenius and $R$. haemaphysaloides were found on dogs. Among adults, more females were present than males. The presence of more females has been reported in the study of Shimada et al. 2003 and the presence of more males has been reported in Dantas-Torres and Otranto 2011 and Diyes \& Rajakaruna 2015. Only nymphs of D. auratus and A. integrum and only adults of $H$. turturis and Hyalomma sp were recorded.

The three-host life cycle of $R$. sanguineus was successfully completed within an average of 98 days (70-126 days) and all three stages fed on the New Zealand white rabbits. The duration of the life cycle was shorter compared to the previous studies where it has taken 162-177 days to complete the life cycle (Troughton and Levin 2007; Dantas-Torres 2008). This might be due to the diverse conditions of temperature and relative humidity in which ticks were maintained, as well as the climatic conditions of different geographic regions. However, there might be also some strain-related differences (Dantas-Torres 2008). The weight of the wild caught females of this study was 133.2 (54-187) mg which is lower than previously recorded values (289.5 mg; Dantas-Torres 2008). Wild caught females were removed deliberately from the host while in the study done by Dantas-Torres et al. females were allowed to naturally drop off after feeding. Number of eggs laid, during this study is in consistent with the previous records however, with a lower mean number (Troughton and Levin 2007; Dantas-Torres 2008). Similarly, recorded pre-oviposition period, incubation period and parasitic periods of all three life stages were lower than previously recorded durations (Troughton and Levin 2007; Dantas-Torres 2008). The REI and RFI were $50.8 \pm 9.69$ (22.0-70.0) and 9.1 \pm 5.01 (0-22.6) respectively. Dantas-Torres 2008, reported a REI of 13 and RFI of 13.2 for same species in Italy. The egg-laying potential of an engorged female is directly related to her capacity to feed; therefore heavier females show highest values in the number of eggs laid as well as the weight of the egg mass, and after that a higher hatch rate. This would explain higher REI, RAI and RFI in Italy population (Gaxiola-Camacho et al, 2009; Dantas-Torres 2008).

The distribution and abundance of dog tick species may depend on many factors such as climatic factors such as temperature, humidity, rainfall, presence of other domestic and wild animals and management practices including usage of acarides and the life cycle can be different from other geographic region according to the different climatic factors present. Moreover, Danta-Torres (2010) highlights that in the era of globalization and climate changes; $R h$. sanguineus is becoming increasingly relevant from a public health perspective. This tick has also been implicated in the transmission of pathogens of zoonotic concern (e.g., $R$. rickettsii) and recent studies have shown that $R h$. sanguineus ticks exposed to high temperatures are more prone to bite humans (Parola et al., 2008). This scenario highlights that the climate change could affect $R h$. sanguineus populations of around the world and, consequently, the epidemiology of certain tick-borne infections (Parola et al., 2008).

\section{Declarations}

Ethics Approval - All the study protocols and objectives were approved by the Institutional Ethical Clearance Committee of postgraduate Institute of Peradeniya, Sri Lanka

Consent to Participate - Not Applicable.

Consent for publication - Not Applicable.

Funding - Financial assistance from the National Research Council (Grant 11-44)

Availability of Data and Material - All data are available in hard copies and soft copies with the principal investigator stored securely releasable upon any reasonable request

Conflicts of Interest - Authors declare that there is no conflict of interest

Code Availability - Not Applicable

Acknowledgements: Financial assistance from National Research Council (Grant 11-44) is acknowledged.

Authors contributions - K.O. Bandaranayaka (Conceptualization, Investigation, data curation, writing the original draft, visualization, formal analysis), U.I. Dissanayake (Investigation, data curation, writing the original draft, visualization, resources) R.S. Rajakaruna (conceptualization, methodology, validation, writing review and editing, supervision, project administration) 


\section{References}

1. Anderson JF, Magnarelli LA. Vertebrate Host Relationships and Distribution of Ixodid Ticks (Acari: Ixodidae) in Connecticut, USA. J Med Entomol. 1980;17:314-23. https://doi.org/10.1093/jmedent/17.4.314.

2. Ariyarathne S, Apanaskevich DA, Amarasinghe PH, Rajakaruna RS. Occurrence and distribution of tick species associated with human otoacariasis in selected districts of Sri Lanka. Experiment Applied Acaralogy. 2016;70(1):99-123. doi:10.1007/s10493-016-0056-z. Epub 2016 Jul 6.

3. Bhat HR, Naik SV, Ilkal MA, Banerjee K. Transmission of Kyasanur Forest disease virus by Rhipicephalus haemaphysaloides ticks. Acta Virologia. 1978;22(3):241-4. PMID: 27975.

4. Černý V, Rosický B, Ašmera J, Kadlčík K, Kobík V, Kratochvílová E, et al. Results of investigations of phenology of the common tick Ixodes ricinus (L.) in the Czech lands in the years 1960-1962. Folia Parasitologia. 1965;12(2):125-31.

5. Daniel M, Materna J, Honig V, Metelka L, Danielová V, Harcarik J, Grubhoffer L. Vertical Distribution of the Tick Ixodes ricinus and Tick-borne Pathogens in the Northern Moravian Mountains Correlated with Climate Warming (Jeseníky Mts., Czech Republic). Cent Eur J Public Health. 2009;17:139-45. 10.21101/cejph.a3550

6. Dantas-Torres F. The brown dog tick, Rhipicephalus sanguineus (Latreille, 1806) (Acari: Ixodidae): from taxonomy to control. Vet Parasitol. 2008;152(34):173-85

7. Dantas-Torres F. Biology and ecology of the brown dog tick, Rhipicephalus sanguineus. Parasites Vectors. 2010;3:26.

8. Dantas-Torres F. Ticks as vectors of Leishmania parasites. Trends in Parasitology. 2011;27(4):155-9.

9. Dantas-Torres F, Chomel B, Otranto D. Ticks and tick-borne diseases: A One Health perspective. Trends Parasitol. 2012;28:437-46. 10.1016/j.pt.2012.07.003.

10. Dantas-Torres F, Otranto D. Rhipicephalus sanguineus on dogs: relationships between attachment sites and tick developmental stages. Exp Appl Acarol. 2011;52:289-397.

11. Dautel H, Dippel C, Oehme R, Hartelt K, Schettler E. Evidence for an increased geographical distribution of Dermacentor reticulatus in Germany and detection of Rickettsia sp. RpA4. International Journal of Medical Microbiology. 2006;296(S1)(2006):149-156.

12. Diyes GCP, Rajakaruna RS. Diversity and distribution of tick species infesting goats with two new host records from Sri Lanka. Journal of National Science Foundation Sri Lanka. 2015;43(3):225-34.

13. Edussuriya BD, Weilgama DJ. Case reports: intra-aural tick infestations in humans in Sri Lanka. Transaction of the Royal Society of Tropical Medicine Hygiene. 2003;97:412-3.

14. Ewing SA, Mathew JS, Panciera RJ. Transmission of Hepatozoon americanum (Apicomplexa: Adeleorina) by ixodids (Acari: Ixodidae). J Med Entomol. 2002;39:631-4.

15. Forlano M, Scofield A, Elisei C, Fernandes KR, Ewing SA, Massard CL. Diagnosis of Hepatozoon spp. in Amblyomma ovale and its experimental transmission in domestic dogs in Brazil. Vet Parasitol. 2005;134:1-7.

16. Gaxiola-Camacho S, García-Vázquez Z, Cruz-Vázquez C, Portillo-Loera J, Vázquez-Peláez C, Quintero-Martínez MT, Rosario-Cruz R. Comparison of efficiency and reproductive aptitude indexes between a reference and field strains of the cattle tick Rhipicephalus (Boophilus) microplus, in Sinaloa, Mexico. Revista Brasileira de Parasitologia Veterinária. 2009;18(4):9-13.

17. Guglielmone AA, Robbins RG, Apanaskevich D, Petney TN, Estada-Pena A, Horak IG, Shao R, Barker SC. The Argasidae, Ixodidae and Nuttalliellidae (Acari: Ixodida) of the world: a list of valid species names. Zootaxa. 2010;2528:1-28.

18. Health Protection Scotland. Glasgaw. United Kingdom. 2009. http://www.documents.hps.scot.nhs.uk/giz/10-year-tables/lyme.pdf. Accessed March 2020.

19. Hsu YM, Lin CC, Chomel BB, Tsai KH, Wu WJ, Huang CG, Chang CC. Identification of Rickettsia felis in fleas but not ticks on stray cats and dogs and the evidence of Rickettsia rhipicephali only in adult stage of Rhipicephalus sanguineus and Rhipicephalus haemaphysaloides. Comparative Immunology Microbiology Infectious Diseases. 2011;34(6):513-8. doi:10.1016/j.cimid.2011.09.005. Epub 2011 Oct 13. PMID: 22000945.

20. Jameson LJ, Medlock JM. Results of HPA tick surveillance in Great Britain. Vet Rec. 2009;165:154.

21. Kirby AD, Smith AA, Benton TG, Hudson PJ. Rising burden of immature sheep ticks (Ixodes ricinus) on red grouse (Lagopus lagopus scoticus) chicks in the Scottish uplands. Medical and Veterinary Entomology. 2004;18(1):67-70; doi: 10.1111/j.0269-283x.2004.0479.x. PMID: 15009449.

22. Koch DL. Systematische Uebersicht fiber die Ordnung der Zecken. Arch. f. Naturg., Berlin, Jahrg. X, Bd.l; 1844:217-239.

23. Labruna MB, Jorge RS, Sana DA, Jácomo AT, Kashivakura CK, Furtado MM, Ferro C, Perez SA, Silveira L, Santos TS Jr, Marques SR, Morato RG, Nava A, Adania CH, Teixeira RH, Gomes AA, Conforti VA, Azevedo FC, Prada CS, Silva JC, Batista AF, Marvulo MF, Morato RL, Alho CJ, Pinter A, Ferreira PM, Ferreira F, Barros-Battesti DM. Ticks (Acari: Ixodida) on wild carnivores in Brazil. Exp Appl Acarol. 2005;36:149-63.

24. Liyanaarachchi DR, Rajakaruna RS, Dikkumbura AW, Rajapakse RPVJ. Ticks infesting wild and domestic animals and humans of Sri Lanka with new host records. Acta Trop. 2015a;142:64-70.

25. Liyanaarachchi DR, Jinadasa HRN, Dilrukshi PRMP, Rajapakse RPVJ. Epidemiological Study on ticks in farm animals in selected areas of Sri Lanka. Tropical Agricultural Research. 2013;24:336-46.

26. Liyanaarachchi DR, Rajakaruna RS, Rajapakse RPVJ. Spotted fever group rickettsia in ticks infesting humans, wild and domesticated animals of Sri Lanka: one health approach. Ceylon Journal of Science (Biological Sciences). 2015b;44(2):67-74.

27. Liu Q, Zhou YQ, Zhou DN, Liu EY, Du K, Chen SG, et al. Semi-nested PCR detection of Babesia orientalis in its natural hosts Rhipicephalus haemaphysaloides and buffalo. Vet Parasitol. 2007;143:260-6. 10.1016/j.vetpar.2006.08.016.

Page $9 / 13$ 
28. Louly CCB, Soares S, Silveira D, Neto O, Silva A, Borges L. Differences in the susceptibility of two breeds of dogs, English cocker spaniel and beagle, to Rhipicephalus sanguineus (Acari: Ixodidae). Int J Acarology. 2009;35:25-32.

29. Matjila TP, Nijhof AM, Taoufik A, Houwers D, Teske E, Penzhorn BL, et al. Autochthonous canine babesiosis in the Netherlands. Vet Parasitol. 2005;131:23-9. https://doi.org/10.1016/j.vetpar.2005.04.020.

30. Parola P, Socolovschi C, Jeanjean L, Bitam I, Fournier PE, Sotto A, Labauge P, Raoult D. Warmer weather linked to tick attack and emergence of severe rickettsioses. PLoS Neglected Tropical Diseases. 2008;2:e338.

31. Pietzsch ME, Medlock JM, Jones L, Avenell D, Abbott J, Harding P, Leach S. Distribution of Ixodes ricinus in the British Isles: investiga-tion of historical records. Med Vet Entomol. 2005;19:306-14 (11) (PDF) British ticks; https://www.researchgate.net/publication/289959651_British_ticks [accessed Oct 05 2020].

32. Regendanz P, Muniz J. Rhipicephalus sanguineus como transmissor da piroplasmose canina no Brasil. Memórias do Instituto Oswaldo Cruz. 1936;31:81-4.

33. Scharlemann J, Johnson P, Smith AA, Macdonald D, Randolph S. Trends in Ixodid tick abundance and distribution in Great Britain. Med Vet Entomol. 2008;22:238-47. 10.1111/j.1365-2915.2008.00734.x.

34. Seneviratne P. The ticks (Ixodoidea) of Ceylon, Part1-Argasidae. Ceylon Veterinary Journal. 1962;X(1):30-41.

35. Seneviratne P. The Ixodidae (Ticks) of Ceylon. Part II and III. Ceylon Veterinary Journal. 1965;XIII(2):28-45.

36. Shaw S, Day M, Birtles R, Breitschwerdt E. Tick-borne diseases of dogs. Trends in Parasitology. 2001;17:74-80. 10.1016/S1471-4922(00)01856-0.

37. Shimada Y, Beppu T, Inokuma H, Okuda M, Onishi T. Ixodid tick species recovered from domestic dogs in Japan. Medican Veterinary Entomology. 2003;17:38-45.

38. Smith FD, Ballantyne R, Morgan ER, Wall R. Prevalence, distribution and risk associated with tick infestation of dogs in Great Britain. Med Vet Entomol. 2011. doi:10.1111/j.1365-2915.2011.00954.x.

39. Sonenshine DE. Biology of Ticks. Vol. I: Oxford University Press; 1991.

40. Sonenshine DE. Biology of Ticks. Vol. II: Oxford University Press; 1991.

41. Troughton D, Levin M. Life Cycles of Seven Ixodid Tick Species (Acari: Ixodidae) Under Standardized Laboratory Conditions. J Med Entomol. 2007;44:732-40. 10.1603/0022-2585(2007)44[732:LCOSIT]2.0.C0;2.

42. Walker A. The Genus Rhipicephalus (Acari, Ixodidae): A Guide to the Brown Ticks of the World; Jane B. Walker, James E. Keirans and Ivan G. Horak Tropical Animal Health Production. 2000;32:417-8; https://doi.org/10.1023/A:1005237804239.

43. Zygner W, Górski P, Wedrychowicz H. Detection of the DNA of Borrelia afzelii, Anaplasma phogocytophilum and Babesia canis in blood samples from dogs in Warsaw. The Veterinary record. 2009;164:465-7; 10.1136/vr.164.15.465.

\section{Figures}
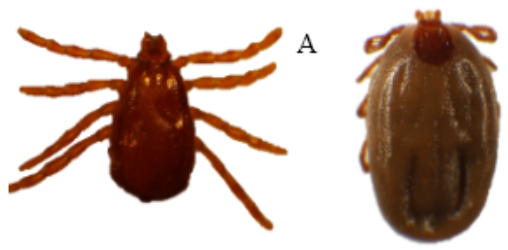

B
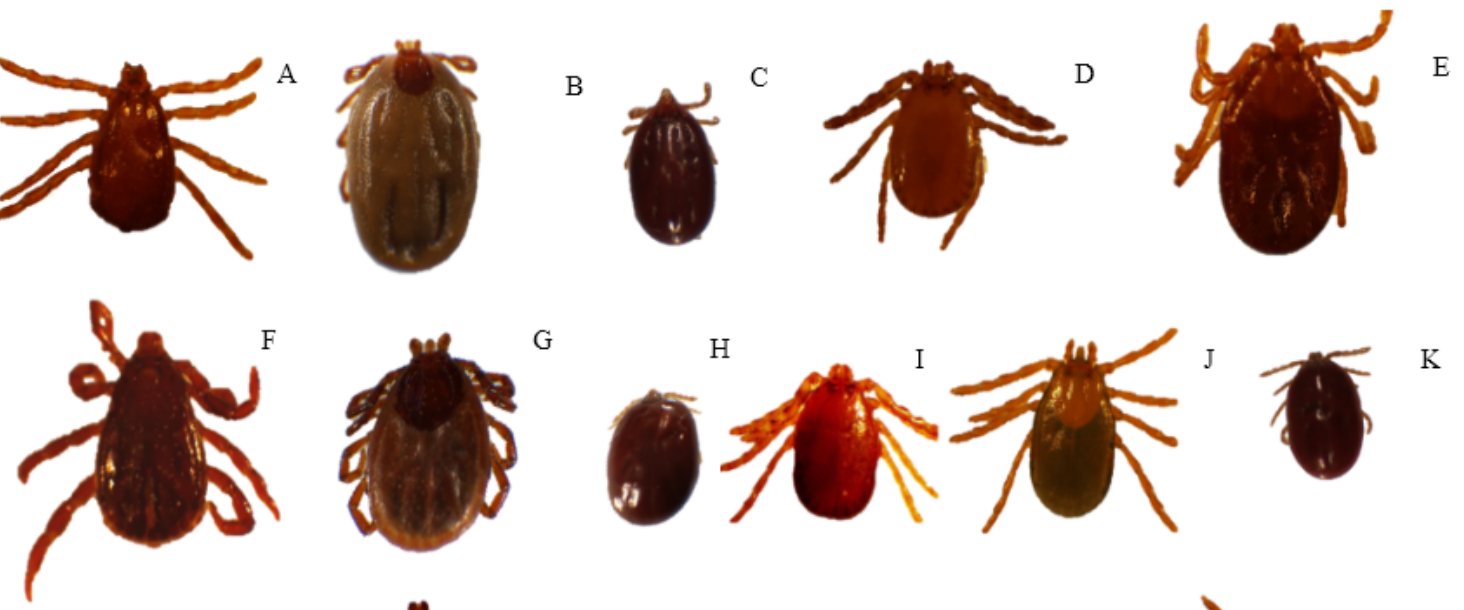

K
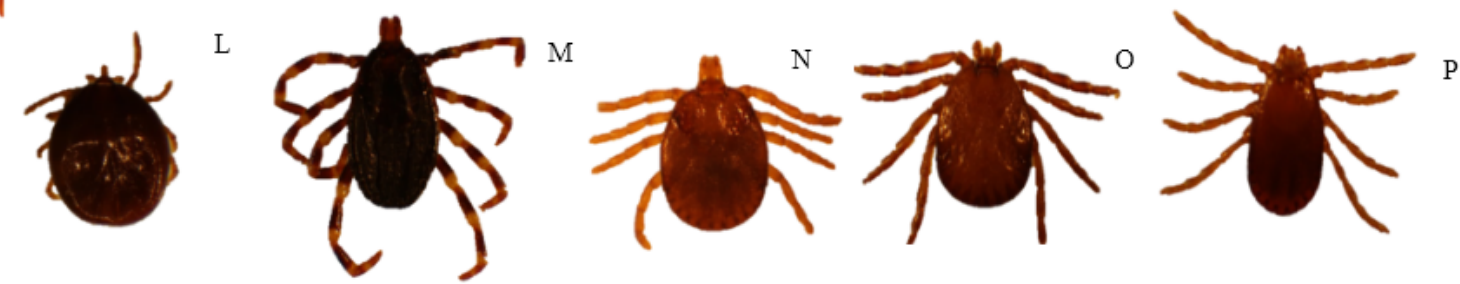

\section{Figure 1}

Rhipicephalus sanguineus, Rhipicephalus haemaphysaloides, Haemaphysalis intermedia, Haemaphysalis bispinosa, Haemaphysalis turturis, Amblyomma integrum, Hyalomma sp. and Dermacentor auratus (Family Ixodidae; Figure 1). 


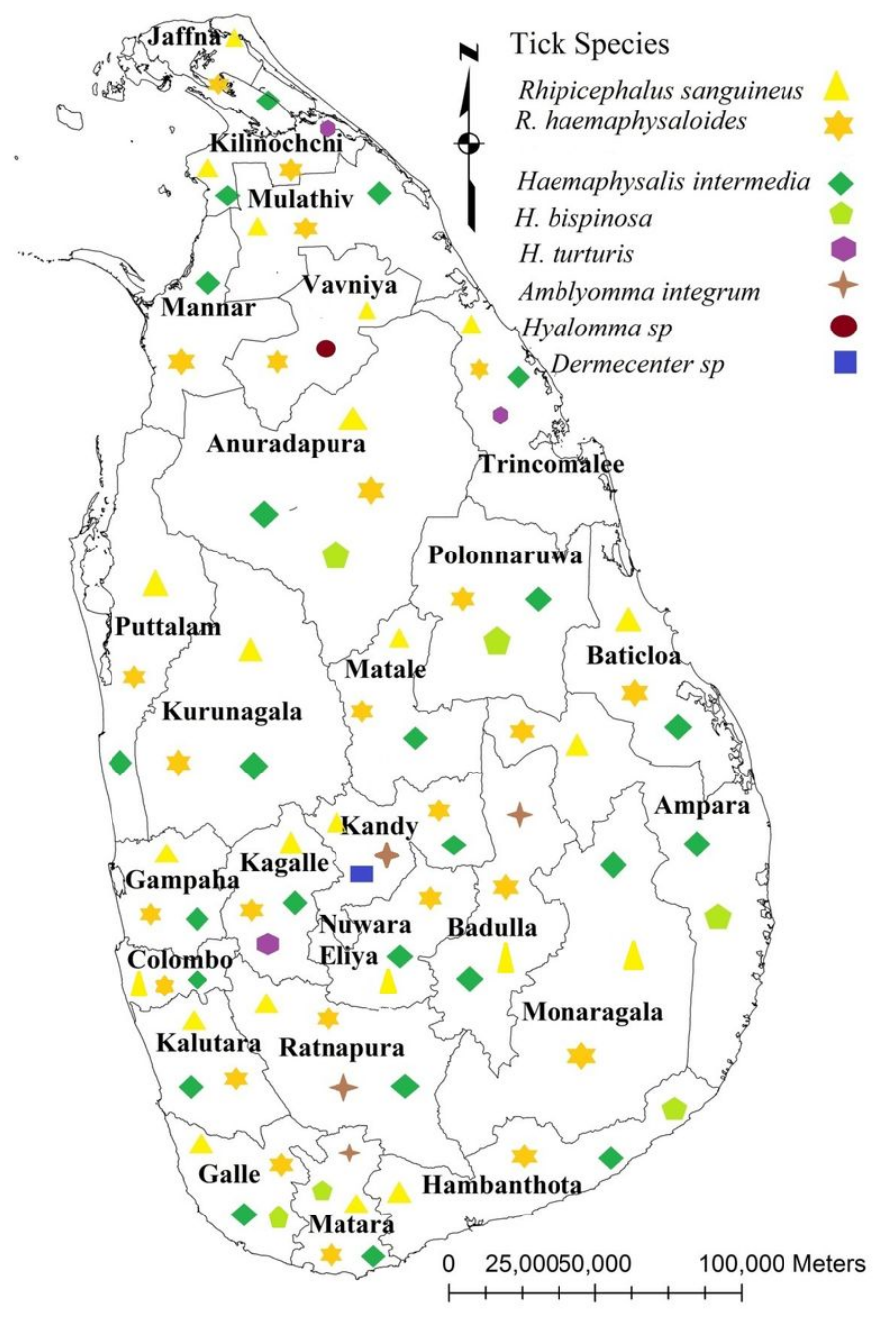

\section{Figure 2}

In these exceptions, R. haemaphysaloides was the dominant species, which was the second most common tick ( $\mathrm{n}=667,22.0 \%)$ infesting dogs in Sri Lanka. The least common species was Hyalomma spp. (0.06\%) found only in the Vavuniya district (Table 3; Figure 2). 


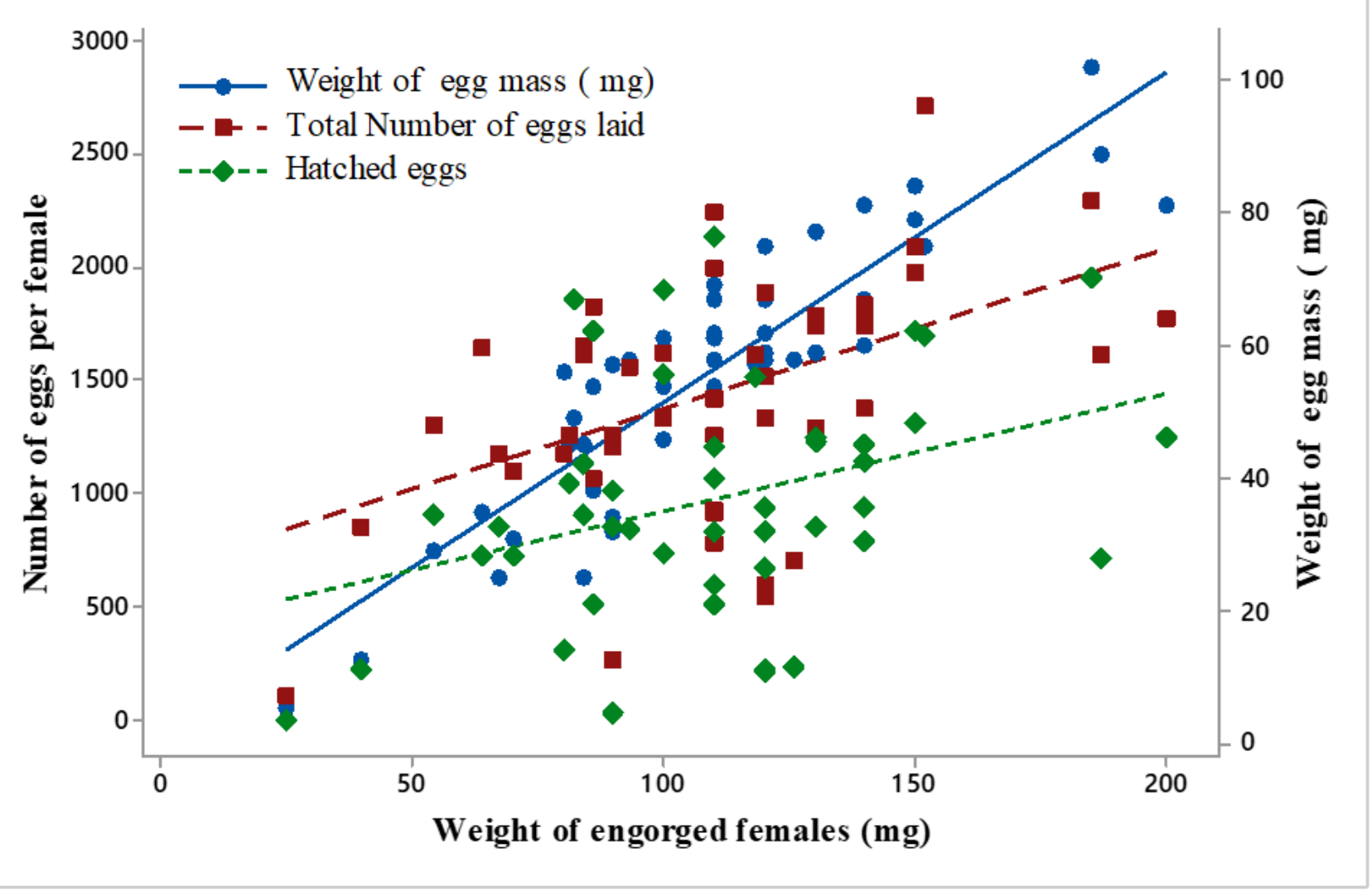

Figure 3

The number of eggs laid increased rapidly within the first three days and gradually decreased. There were positive correlations found between the female weight and three reproductive parameters tested; the total number of eggs laid, the number of eggs hatched, and the weight of the egg mass (Pearson correlation: $r=0.468,0.355,0.896$ respectively; $p<0.05$ : Table 6, Figure 3). 


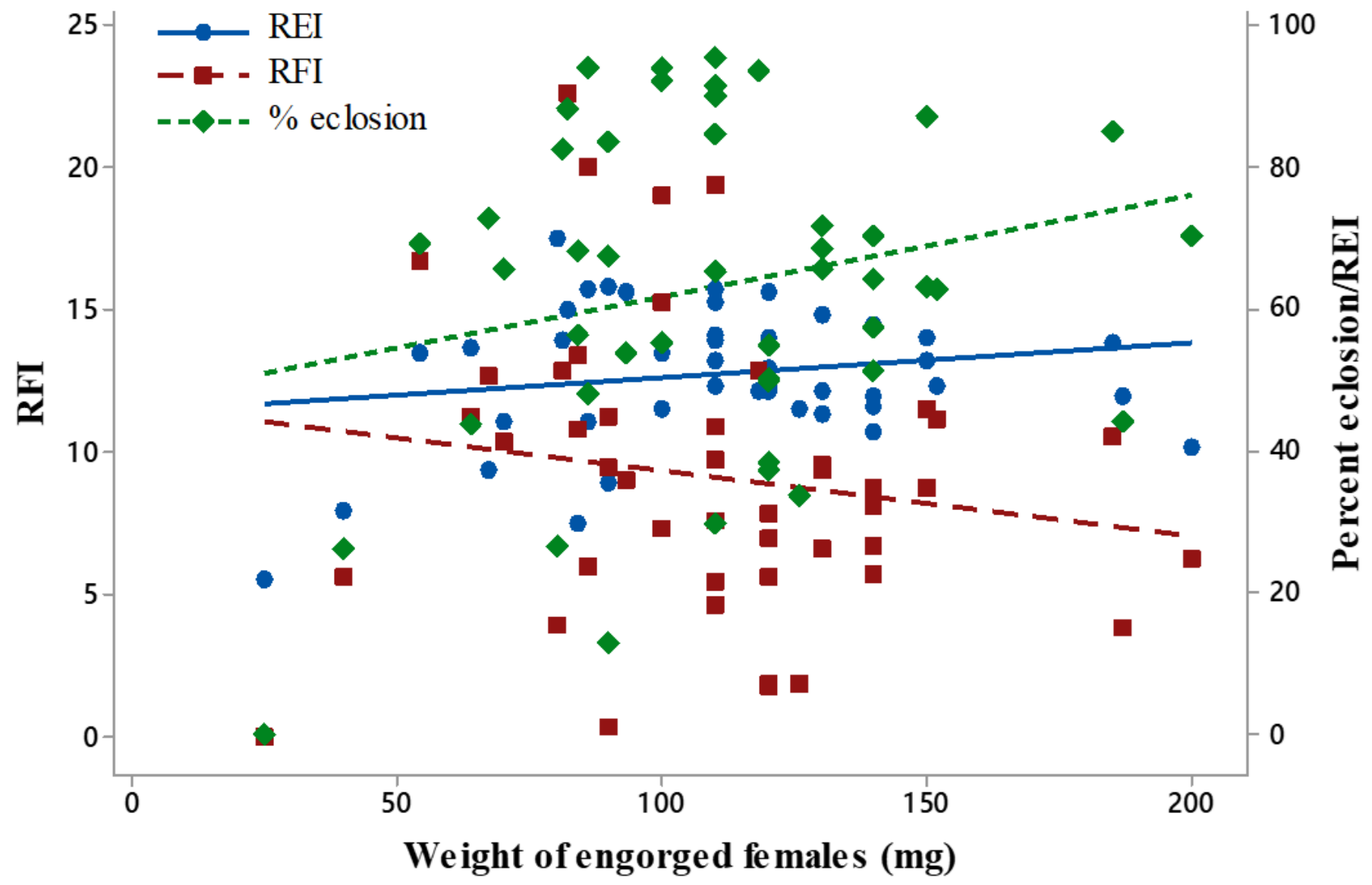

Figure 4

Nonetheless, the regression fit does not fully explain REI, RFI or percent eclosion since the R2 values were $<5.0 \%$ (Figure 4).

\section{Supplementary Files}

This is a list of supplementary files associated with this preprint. Click to download.

- Graphicalabstract.pptx 